\title{
Maternal morbidity due to unsafe medical abortion in rural practice is just the tip of the iceberg: is it really preventable?
}

\author{
Meena Armo ${ }^{1 *}$, Kavita Babbar ${ }^{1}$, Hemlata Thakur ${ }^{2}$, Sachin Pandey ${ }^{2}$
}

\author{
${ }^{1}$ Department of Obstetrics \& Gynecology, Chhattisgarh Institute of Medical Sciences, Bilaspur-495001, Chhattisgarh, \\ India \\ ${ }^{2}$ Department of Community Health, Chhattisgarh Institute of Medical Sciences, Bilaspur-495001, Chhattisgarh, India
}

Received: 10 November 2014

Accepted: 10 December 2014

\author{
*Correspondence: \\ Dr. Meena Armo, \\ E-mail: drmeenaarmo@gmail.com, priya_d143@yahoo.com
}

Copyright: (C) the author(s), publisher and licensee Medip Academy. This is an open-access article distributed under the terms of the Creative Commons Attribution Non-Commercial License, which permits unrestricted non-commercial use, distribution, and reproduction in any medium, provided the original work is properly cited.

\begin{abstract}
Background: In India around 6.4 million abortions are performed annually, of which 3.6 million (56\%) were unsafe abortions, account for $8-20 \%$ of all maternal deaths. Medical methods of abortion have been proven to be effective and safe option to save women's lives when practiced under medical supervision. This study was carried out to determine the frequency of unsafe medical abortion, demographic profile of patients, reasons for seeking abortion, abortion providers, evaluation of significant adverse outcome and management.

Methods: A 5 year retrospective observational study included 400 patients with history of unsafe medical abortion who were admitted with complications between June 2009 and May 2014, in the department of obstetrics and gynecology, government medical college (Chhattisgarh institute of medical sciences) and tertiary care hospital Bilaspur Chhattisgarh.

Results: Unintended pregnancy was the main reason for the unsafe medical abortion in 378 (94.5\%) women. Most frequent complains observed for admission were heavy bleeding and retained products (incomplete abortion). Major complications seen in $177(44.25 \%)$ cases only, of which moderate to severe anaemia in 141 (35.25\%), shock in 23 (5.75\%), septicaemia in $11(2.75 \%)$ and acute renal failure in $2(0.5 \%)$ cases. Majority $206(51.50 \%)$ required surgical intervention. However $5(1.25 \%)$ patients could not survive despite of all resuscitative measures. Post-abortion family planning adopted by 27 (6.75\%) cases only.

Conclusions: Mostly unsafe abortions take place behind the scene, always remain unnoticed and never listed in government data. In Chhattisgarh state where majority of rural population are tribal, illiterate, living in difficult to reach areas, unaware of safe abortion and abortion rights and dependent on herbs, quacks or paramedics, due to unavailability of clinicians or lady medical officers in government facilities. Thus the best way remain to prevent unsafe abortion is the prevention of unwanted pregnancy.
\end{abstract}

Keywords: Unsafe abortion, Medical methods of abortion, Maternal morbidity

\section{INTRODUCTION}

Globally, 42 million women undergo an induced abortion each year; of which 19 million are unsafe abortions, account for $13 \%$ of all maternal deaths. ${ }^{1}$ In India around 6.4 million abortions are performed annually, of which 3.6 million or $56 \%$ are unsafe, account for $8-20 \%$ of all maternal deaths. ${ }^{2}$ In Chhattisgarh, despite of very high
MMR, the percetage of abortion is only $2.1 \%$, which is very low as compare to the other EAG (Economic action group) states of India probably because of underreporting of abortion. ${ }^{3}$

Since 1988 medical abortion has offered a safer and more cost effective option. DCI approved the use of mifepristone in April 2002 and misoprostol in Dec 2006 for termination of pregnancy up to 49 days gestation 
period. In Dec 2008 this combipack was approved for the medical termination of pregnancy up to 63 days gestation.

As per the original MTP Act of India, only obstetrician and gynecologist and registered medical practitioner as defined by the MTP Act, can only prescribe the MAP. Although amended MTP rules 2003 allow providers to offer medical abortion at uncertified clinic as long as they have access to certified centre for backups for extending the safe abortion services nationwide. ${ }^{4}$ However these drugs are widely available Over The Counter (OTC) and its unsupervised consumption is rising particularly in rural areas. ${ }^{5,6}$

The aim of this study was to determine the frequency of women who had undergone unsafe medical abortion and later attended a tertiary care hospital with associated complications. This study also highlights the need of improvement in existing MTP services especially in rural areas like our state.

\section{METHODS}

A 5 year retrospective observational study included 400 patients with history of unsafe medical abortion who were admitted between June 2009 and May 2014 mostly as an emergency, in the department of obstetrics and gynecology of Chhattisgarh institute of medical sciences a government medical college and $2^{\text {nd }}$ biggest tertiary care hospital, with complains that can be attributed to abortion such as severe vaginal bleeding, lower abdominal cramp, fever, incomplete abortion and for blood transfusion. Each case was thoroughly evaluated on the basis of age, marital status, residence, religion, education, socio-economic status, gestational age at the time of termination, the reason for termination and providers. After a thorough review of examination, investigation and treatment records, the details of the outcome including maternal morbidity and mortality were recorded and discussed. Qualitative data were presented as frequencies and percentages.

\section{RESULTS}

The present study was conducted in the department of obstetrics and gynecology, a government medical college (Chhattisgarh institute of medical sciences) and tertiary care hospital, Bilaspur, Chhattisgarh, from June 2009 to May 2014. Out of 758 cases of abortion observed over a period of 5 years, $400(52.77 \%)$ women had undergone an unsafe medical abortion outside the institute and later admitted in the hospital for complications.

The mean age of women was $26.47 \pm 6.23$ years in our study. Majority of patients $368(92.0 \%)$ were Hindu, married $366(91.5 \%)$, uneducated $231(57.8 \%)$, rural 257 $(63.3 \%)$ and $260(65.0 \%)$ from very low socioeconomic background. Surprisingly most of the women were either from the scheduled cast or from other backward cast; however contribution from the tribal community were only 40 (11.8\%) (Table 1).

Table 1: Demographic details $(\mathrm{N}=400)$.

\begin{tabular}{|c|c|c|}
\hline & Frequency & Percentage \\
\hline \multicolumn{3}{|c|}{ Age (years) (Mean age $26.47 \pm 6.23$ ) } \\
\hline $20-29$ & 246 & 61.0 \\
\hline $30-39$ & 105 & 26.3 \\
\hline$\geq 40$ & 12 & 3.0 \\
\hline \multicolumn{3}{|l|}{ Marital status } \\
\hline Married & 366 & 91.5 \\
\hline Unmarried & 24 & 6.0 \\
\hline Divorce/widow & 10 & 4.0 \\
\hline \multicolumn{3}{|l|}{ Educational status } \\
\hline Educated & 169 & 42.2 \\
\hline Uneducated & 231 & 57.8 \\
\hline \multicolumn{3}{|l|}{ Residence } \\
\hline Urban & 143 & 35.8 \\
\hline Rural & 257 & 64.3 \\
\hline \multicolumn{3}{|l|}{ Religion } \\
\hline Hindu & 368 & 92.0 \\
\hline Muslim & 25 & 6.3 \\
\hline Christian & 7 & 1.8 \\
\hline \multicolumn{3}{|l|}{ Caste } \\
\hline ST & 47 & 11.8 \\
\hline $\mathrm{SC}$ & 125 & 31.3 \\
\hline $\mathrm{OBC}$ & 122 & 30.5 \\
\hline Others & 106 & \\
\hline \multicolumn{3}{|l|}{ Socioeconomic status } \\
\hline Low socioeconomic status & 260 & 65.0 \\
\hline Lower middle & 106 & 26.5 \\
\hline Middle & 34 & 8.5 \\
\hline
\end{tabular}

In our study, majority $289(72.3 \%)$ had a parity of $1-3,71$ $(17.8 \%)$ women were nulliparous, $36(9 \%)$ were grand multipara and remaining $4(1 \%)$ had parity of 7 or more. Majority (68.8\%) had abortions in the first trimester similar as other studies. Unintended pregnancy was the reason for the abortion in 378 (94.4\%), majority had used abortion as a method of birth spacing or limiting family size, unfortunately rest of $22(5.5 \%)$ had undergone abortion due to sex preference. Providers were Nurse or ANM in $130(32.5 \%)$ cases, quacks in $76(19.0 \%)$ and untrained allopathic doctors/RMA/Ayush doctors in $53(13.3 \%)$ only (Figure 1). Majority of the women 141 $(35.3 \%)$ had taken MAP either as self-medication or used as OTC drug (Table 2).

Most common complaint for admission were heavy bleeding seen in $250(62.5 \%)$ women, USG diagnosed retained products for evacuation in 54 (13.5\%), severe abdominal pain in $40(10.0 \%)$ women. Patients admitted for blood transfusion were $35(8.8 \%)$ and for fever were $20(5.3 \%)$ (Table 3$)$. 


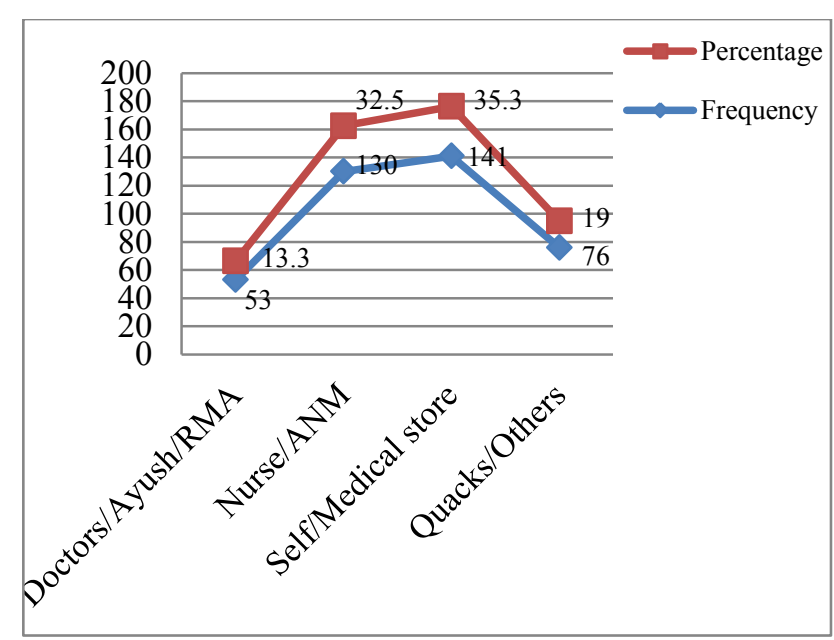

Figure 1: Frequency and percentage of abortion providers.

Table 2: Parity, gestational weeks, reasons for termination $(\mathrm{N}=\mathbf{4 0 0})$.

\begin{tabular}{|lll|}
\hline \multicolumn{2}{l}{ Frequency } & Percentage \\
\hline 0 & & \\
\hline $1-3$ & 71 & 17.8 \\
\hline $4-6$ & 289 & 72.3 \\
\hline$\geq 7$ & 36 & 9.0 \\
\hline Gestational weeks at termination & 1.0 \\
\hline$\leq 12$ weeks & 4 & 68.8 \\
\hline $13-20$ weeks & 113 & 28.3 \\
\hline$\geq 21$ weeks & 12 & 3.0 \\
\hline Reasons for seeking termination & \\
\hline Unmarried & 24 & 6.0 \\
\hline Divorced/widow & 10 & 4.0 \\
\hline Contraceptive failure & 58 & 14.5 \\
\hline $\begin{array}{l}\text { Lactating/ignorant of being } \\
\text { pregnant }\end{array}$ & 84 & 21.0 \\
\hline Birth spacing & 105 & 26.3 \\
\hline $\begin{array}{l}\text { Unaware of contraceptive } \\
\text { methods }\end{array}$ & 97 & 24.3 \\
\hline Sex preference & 22 & 5.5 \\
\hline
\end{tabular}

Table 3: Chief complaints at admission $(\mathrm{N}=400)$.

\begin{tabular}{|lll|}
\hline Complaints & Frequency & Percentage \\
\hline Heavy bleeding & 250 & 62.5 \\
\hline Abdominal cramps & 40 & 10.0 \\
\hline Fever/chills & 21 & 5.3 \\
\hline For blood transfusion & 28 & 7.0 \\
\hline Retained products & 54 & 13.5 \\
\hline Failure & 07 & 1.7 \\
\hline
\end{tabular}

Overall major complications observed in 177 (44.25\%) cases only, of which moderate to severe anaemia seen in $141(35.25 \%)$, shock in $23(5.75 \%)$, septicaemia in 11
$(2.75 \%)$ and acute renal failure in $2(0.5 \%)$ cases (Table 4).

Table 4: Major complications* and mortality $(\mathrm{N}=400)$.

\begin{tabular}{|lllll|} 
Complication & Frequency & $\%$ & Mortality & $\%$ \\
\hline Moderate anemia & 62 & 15.5 & & \\
\hline Severe anemia & 79 & 19.75 & & \\
\hline Shock & 23 & 5.75 & 3 & 0.75 \\
\hline Septicemia & 11 & 2.75 & 2 & 0.5 \\
\hline Acute renal failure & 2 & 0.5 & & \\
\hline Total & 177 & 44.25 & 5 & 1.25 \\
\hline
\end{tabular}

Majority $201 \quad(50.25 \%)$ were required surgical evacuation, $111(27.75 \%)$ required medical management and $15(3.80 \%)$ cases needed intensive care. Laparotomy with salpingectomy performed for ruptured ectopic pregnancy in $2(0.50 \%)$ and $78(19.50 \%)$ patients didn't require any intervention at all. However 5 (1.25\%) patients could not survive despite of all resuscitative measures (Table 5).

Table 5: Management $(\mathrm{N}=400)$.

\begin{tabular}{|lll|}
\hline Interventions & Frequency & Percentage \\
\hline Observation only & 78 & 19.50 \\
\hline $\begin{array}{l}\text { Medical interventions } \\
+ \text { anemia correction }\end{array}$ & 111 & 27.75 \\
\hline Intensive care & 15 & 3.80 \\
\hline Surgical evacuation & 201 & 50.25 \\
\hline $\begin{array}{l}\text { Hysterotomy with } \\
\text { tubectomy }\end{array}$ & 03 & 0.75 \\
\hline $\begin{array}{l}\text { Laparotomy and } \\
\text { salpingectomy }\end{array}$ & 02 & 0.50 \\
\hline
\end{tabular}

Post-abortion contraception was advised to all cases however IUCD insertion was done in $10(2.5 \%)$ and injectable contraceptive (DMPA) was given to $14(3.5 \%)$, hysterotomy with tubectomy done in $3(0.75 \%)$ cases and the rest refused for adopting any method of contraception (Table 6).

Table 6: Frequency and percentage of post-abortal contraception $(\mathrm{N}=400)$.

\begin{tabular}{|lll|}
\hline IUCD insertion & Frequency & Percentage \\
\hline Injectable contraceptive & 10 & 2.5 \\
\hline Hysterotomy with tubectomy & 14 & 3.5 \\
\hline
\end{tabular}

\section{DISCUSSION}

Abortion is identified as one of the most neglected women's health issues in India and around 10000-12000 women die every year due to unsafe abortion. ${ }^{7}$ However various studies say that there are actually six times many abortions performed. ${ }^{8}$ In Chhattisgarh, of 25.5 milion population $78 \%$ live in rural areas, $37 \%$ account for tribal 
population. As per APIP 2012-2013 Chhattisgarh, there are 27 districts, 146 blocks, and 20308 villages. More than half of these districts have been classified as remote, tribal, and extremist affected areas. In the state 13 district hospitals and 46 community health canters have the facilitation for abortions, although, these services are not at all properly utilised by most of the village people either unknowingly or they are unable to reach. However, despite of very high MMR that is 269 as compared to 212 for India, the percentage of abortion in Chhattisgarh is only $2.1 \%$, which is very low, probably because of underreporting. ${ }^{3}$ There is also widespread prevalence of domestic violence, about $30 \%$ of ever-married women have experienced spousal violence. Thus despite the liberalization of abortion services since the early 1970 , access to safe abortion services remain limited for the majority of Indian women particularly in rural areas like in our state. ${ }^{9,10}$

As per WHO, medical methods of abortion have been proven to be safe and effective when practiced under medical supervision. It gives more freedom and privacy and has become more common in both legal and illegal procedures may be because of its Over The Counter sale (OTC), which is a very common practice in rural areas where safe abortion services are limited.

In our study 400 or $52.77 \%$ women had undergone an unsafe abortion outside the institute which indicate that unsafe abortion is still continue to outnumber safe and legal abortion in our state too. Most women in our study were between 20-29 years of age group, 366 (91.5\%) women were married while $24(6 \%)$ were unmarried and majority $275(68.8 \%)$ had sought abortions in the first trimester. ${ }^{11}$ The advanced gestation at the time of abortion observed in $113(28.3 \%)$ women could be due to lack of knowledge, inaccessible medical services and sex preference which was observed in 22 (5.5\%)cases despite the child sex ratio as per census being very good in our state. Although no confirmatory evidence was available, these patients had undergone second trimester ultrasound before abortion and the patient did not reveal the sex of the aborted fetus. This data is slightly higher than the other study, suggest that a majority of abortion are either not reported or taken place illegally., ${ }^{3,12}$ In our study $80 \%$ of women had sought abortion because they were from very low socioeconomic status and didn't want a child at that time, either to limit family size or for spacing suggest a high unmet need for family planning. ${ }^{13,14}$

As abortion is just another social stigma of our society, females prefer to go to lady doctor for the same. According to DLHS-3 Chhattisgarh, of 251 PHC's only $17(6.8 \%)$ lady medical officers were posted in the state whereas no lady medical officer was available in any of 16 PHC's of our district Bilaspur. Thus in the present study, majority $259(64.75 \%)$ were easily accessible and unqualified providers, whereas $141(35.3 \%)$ women had taken pills at home as per instructions given by husband or pharmacist. ${ }^{15,16}$ Various studies indicate that unsafe abortion is associated with high morbidity than mortality, higher rate of hospitalization for abortion-related complications seen in rural women. ${ }^{12,14,17}$ Most frequent complains for admission were heavy vaginal bleeding and incomplete abortion which could be due to higher gestation age, self-medication and erratic drug schedule, ${ }^{18,19}$ whereas most frequent complications observed were moderate to severe anaemia which required iron therapy and blood transfusion in 141 $(31.25 \%)$ women. True drug failure observed in 7 $(1.70 \%)$ cases required surgical intervention, undiagnosed ectopic pregnancy needed emergency laparotomy in 2 cases similar as this study. ${ }^{20}$ Surgical curettage performed in $201(50.25 \%)$ women which was quite high if we compare it with other study where medical abortion was performed under supervision. ${ }^{21}$ Despite all measures taken to rectify the complications, 5 patients could not survive giving a mortality rate of $1.25 \%$. Out of 5,3 were died due to irreversible shock as a result of severe blood loss, 2 patients were not responded to higher antibiotics and died because of septicaemia. Hence it appears that medical abortion highlights the need for vigilance and early access to medical help to control morbidity and mortality. ${ }^{22}$

Regarding acceptance of post-abortion family planning methods, only $27(6.75 \%)$ seekers opted which is significantly lower than that reported in other studies. The reasons are not very clear, may be attributed to inadequate counselling done at the time of abortion. ${ }^{22,23}$

\section{CONCLUSION}

Mostly unsafe abortions take place behind the scene, always remain unnoticed and never listed in government data. Thus it appears to the world that situation is under control and the maternal morbidity and mortality are on check.

In Chhattisgarh state where majority of rural population are tribal, illiterate, living in difficult to reach areas, unaware of safe abortion and abortion rights still dependent on herbs, quacks or paramedics due to unavailability of clinicians or lady medical officers in government facilities. Moreover they poorly participate in public health interventions carried out by the government due to lack of confidentiality and insistence on adopting FP method or permanent sterilization. Thus the best way remain to prevent unsafe abortion is the prevention of unwanted pregnancy. Newspapers, Media can play a vital role in creating awareness to remove myths or misconception about contraceptive methods. Over the counter sale of MAP must be banned. Arrangements could be made to increase the base of legal MTP providers for first trimester medical abortion only. However further research is needed to have a clear database in this regard. 


\section{ACKNOWLEDGEMENTS}

We sincerely thank Lt. Col. (Prof.) Dr. S. K. Mohanty, dean and prof. Dr. R. Murthy, medical superintendent CIMS, for granting permission. We also thank all interns for collecting the records.

\section{Funding: No funding sources}

Conflict of interest: None declared

Ethical approval: The study was approved by the institutional ethics committee

\section{REFERENCES}

1. World health organization. Unsafe abortion: global and regional estimates of the incidence of unsafe abortion and associated mortality in 2000. In: WHO, eds. WHO Book. 4th ed. Geneva; World Health Organization; 2004.

2. Duggal R, Ramchandran V. The abortion assessment project-India: key findings and recommendation. Reprod Health Matters. 2004;12(24):122-9.

3. Census India. Annual health survey 2011-2012 fact sheet, Chhattisgarh, vital statistics division, office of the registrar general and census commissioner, New Delhi, India. Available at: www.censusindia.gov.in. Accessed 23 August 2014.

4. Government of India. The medical termination of pregnancy rules, 2003. Vide G.S.R.485 (E), the Gazette of India, 2003;Sec 3( i ):Extra pt.11.

5. Santhya KG, Verma S. Induced abortion: the current scenario in India, look back: looking forward: A profile of sexual and reproductive health in India. Regional Health Forum. 2004;8(2):1-14.

6. Ganatra B, Manning V, Prasad S. Availability of medical abortion pills and the role of Chemists. A study from Bihar and Jharkhand, India. Reprod Health Matters. 2005;13(25):65-74.

7. Banerjee S. Increasing access to safe abortion services in Uttarakhand: identifying medical termination of pregnancy (MTP) training centers. New Delhi: IPAS India; 2007.

8. Kumar N. Current abortion practices in India: a review of literature. Int J Reprod Contracept Obstet Gynecol. 2014 Jun;3(2):293-300.

9. International Institute for Population Sciences (IIPS). District level household and facility survey (DLHS-3), 2007-08: India. Chhattisgarh: Mumbai: IIPS, 2010. Available at: http://www.rchiips.org. Accessed 8 November 2014.

10. Galhotra A, Padhy GK, Pal AK, Giri AK, Nagarkar NM. Mapping the health indicators of Chhattisgarh: a public health perspective. Int J Med Public Health. 2014 JanMar;4(1):23-8.

11. Jain V, Saha SC, Bagga R, Gopalan S. Unsafe abortion: a neglected tragedy, review from a tertiary care hospital in India. J Obstet Gynecol. 2004;30(3):197-201.

12. Saha S, Duggal R, Mishra M. Abortion in Maharashtra: incidence, care and cost. In: Saha S, Dugga R, Mishra M, eds. CEHAT Report. Mumbai: Centre for Enquiry into Health and Allied Themes (CEHAT); 2004: 1-23.

13. Sushanta KB, Clark KA, Warvadekar J. Results of a government and NGO partnership for provision of safe abortion services in Uttarakhand, India: a pre and postintervention evaluation of increasing access to safe abortion services (IASAS) program. In: Sushanta KB, Clark KA, Warvadekar J, eds. IASAS Results. New Delhi, IPAS; 2009.

14. Elul B, Bracken H, Verma S, Ved R, Singhi R, Lockwood $\mathrm{K}$. Unwanted pregnancy and induced abortion in Rajasthan, India. In: Elul B, Bracken H, Verma S, Ved R, Singhi R, Lockwood K, eds. Population Council Report. New Delhi: Population Council; 2004: 31-32.

15. Boler T, Marston C, Corby N, Gardiner E. Medical abortion in India: a model for the rest of the world? London: Marie Stopes International; 2009.

16. Sebastian MP, Khan ME, Sebastian D. Unintended pregnancy and abortion in India with focus on Bihar Madhya Pradesh and Odisha. In: Sebastian MP, Khan ME, Sebastian D, eds. Country Profile Report. New Delhi, India: Population Council; 2014.

17. Grimes DA, Bensen J, Singh S, Romero M, Ganatra B, Okonofua FE, et al. Unsafe abortion: preventable pandemic. Lancet. 2006;368(9550):1908-19.

18. Niinimäki M, Pouta A, Bloigu A, Gissler M, Hemminki $\mathrm{E}$, Suhonen S, et al. Immediate complications after medical compared with surgical termination of pregnancy. Obstet Gynecol. 2009 Oct;114(4):795-803.

19. Sharma R, Verma U, Khajuria B. Medical termination of pregnancy with mifepristone-misoprostol in rural India. J Clin Diagn Res. 2008 June;(3):901-4.

20. Cleland K, Creinin DM, Nucatola D, Nshom M, Trussell J. Significant adverse events and outcomes after medical abortion: Obstet Gynecol. 2012;120(6):1-7.

21. Despande S, Yelikar K, Deshmukh A, Kawde K. Comparative study of medical abortion by mifepristone with vaginal misoprostol in women $<49$ days verses 50-63 days of amenorrhoea. J Obstet Gynecol India. 2010;60(5):403-7.

22. Jejeebhoy SJ, Francis Zavier AJ, Acharya R, Kalyanwala $\mathrm{S}$. Increasing access to safe abortion in rural Maharashtra: outcomes of a comprehensive abortion care model. In: Jejeebhoy SJ, Francis Zavier AJ, Acharya R, Kalyanwala $\mathrm{S}$, eds. Population Council Outcome. New Delhi: Population Council; 2011: 1-69.

23. Holla R, Kanchan T, Unnikrishnan B, Kotian S, Kumar N, Thapar R, et al. Profile of women seeking medical termination of pregnancy in South India. Int J Gynecol Obstet. 2014;125(3):253-5.

DOI: $10.5455 / 2320-1770 . \mathrm{ijrcog} 20150211$

Cite this article as: Armo M, Babbar $\mathrm{K}$, Thakur $\mathrm{H}$, Pandey S. Maternal morbidity due to unsafe medical abortion in rural practice is just the tip of the iceberg: is it really preventable? Int J Reprod Contracept Obstet Gynecol 2015;4:56-60. 